\title{
Prevalence and risk factors of vitamin D insufficiency and deficiency among 6-24-month-old underweight and normal-weight children living in an urban slum of Bangladesh
}

\author{
AM Shamsir Ahmed ${ }^{1,2, *}$, Tahmeed Ahmed ${ }^{2}$, Kurt Z Long ${ }^{2,3}$, \\ Ricardo J Soares Magalhaes ${ }^{4,5}$, Md lqbal Hossain ${ }^{2}$, Md Munirul Islam², \\ Mustafa Mahfuz ${ }^{2}$, SM Abdul Gaffar ${ }^{2}$, Atiya Sharmeen ${ }^{2}$, Rashidul Haque ${ }^{2}$, \\ Richard L Guerrant ${ }^{6}$, William A Petri Jr ${ }^{6}$ and Abdullah Al Mamun ${ }^{1,2}$ \\ 'School of Public Health, University of Queensland, Room 409, Level 4, School of Public Health Building, Herston \\ Road, Herston, Brisbane, QLD 4006, Australia: ${ }^{2}$ Centre for Nutrition and Food Security, International Centre for \\ Diarrheal Disease Research, Bangladesh (icddr,b), GPO Box 128, Dhaka, Bangladesh: ${ }^{3}$ Department of \\ Epidemiology and Public Health, Swiss Tropical and Public Health Institute, Basel, Switzerland: ${ }^{4}$ School of Veterinary \\ Science, University of Queensland, Gatton, Queensland, Australia: ${ }^{5}$ Children's Health and Environment Program, \\ Queensland Children's Medical Research Institute, University of Queensland, Brisbane, Queensland, Australia: \\ ${ }^{6}$ Division of Infectious Diseases and International Health, Department of Internal Medicine, University of Virginia, \\ Charlottesville, VA, USA
}

Submitted 11 May 2015: Final revision received 23 October 2015: Accepted 27 0ctober 2015: First published online 25 November 2015

\begin{abstract}
Objective: We quantified the prevalence of vitamin D status in 6-24-month-old underweight and normal-weight children and identified the socio-economic and dietary predictors for status.

Design: Cross-sectional, baseline data from a nutritional intervention study were analysed. Multinomial logistic regression was used to estimate the odds of being vitamin D deficient or insufficient with the reference being vitamin D sufficient. Setting: Urban slum area of Mirpur field site, Dhaka, Bangladesh.

Subjects: Underweight (weight-for-age $Z$-score $<-2 \cdot 00$ ) and normal-weight (weight-for-age $Z$-score $\geq-1 \cdot 00$ ) children aged 6-24 months.

Results: Among 468 underweight children, 23.1\% were sufficient, $42 \cdot 3 \%$ insufficient, $31.2 \%$ deficient and $3.4 \%$ severely vitamin D deficient. Among 445 normal-weight children, 14.8\% were sufficient, 39.6\% insufficient and 40.0\% deficient and 5.6\% severely deficient. With adjusted multinominal regression analysis, risk factors (OR (95\% CI)) for vitamin D deficiency in underweight children were: older age group (18-24 months old; $2.9(1.5-5.7))$; measurement of vitamin D status during winter (3.0 (1.4-6.4)) and spring (6.9 (3.0-16.1)); and maternal education ( $\geq 6$ years of institutional education; $2 \cdot 2(1 \cdot 0-4 \cdot 9))$. In normal-weight children, older age group (3.6 (1.2-10.6)) and living in the richest quintile $(3.7(1 \cdot 1-12 \cdot 5))$ were found to be significantly associated with vitamin D insufficiency.

Conclusions: The study demonstrates a significant burden of vitamin D insufficiency and deficiency in both underweight and normal-weight children $<2$ years of age from an urban slum of Bangladesh. Identification of risk factors may help in mitigating the important burden in such children.
\end{abstract}

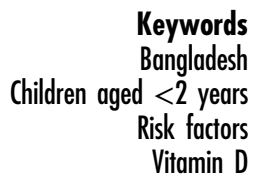

The primary role of vitamin D in the human body is to maintain extracellular Ca levels but recently it has been implicated to have a non-skeletal role including protection from infectious, inflammatory and neoplastic disease outcomes $^{(1-4)}$. In man, vitamin D is primarily synthesized by the skin through exposure to sunlight (UV-B radiation, wavelength $290-315 \mathrm{~nm}$ ) while only a small fraction (5-10\%) comes from the $\operatorname{diet}^{(1)}$. Recently a study estimated that 4 billion cases of bone disease (rickets, osteomalacia and osteoporosis) and 3.3 billion disabilityadjusted life years are lost globally due to vitamin D deficiency that results from reduced UV exposure ${ }^{(5)}$.

The prevalence of vitamin D deficiency among children and adults varies significantly worldwide due to variation in sunlight exposure during the year and insufficient presence of corrective programmes ${ }^{(1,6-9)}$. Several small studies in the 
Indian subcontinent, including Bangladesh, have reported wide variation (as low as $2 \%$ to $84 \%$ ) in the prevalence of vitamin $\mathrm{D}$ deficiency and insufficiency among pre-school children ${ }^{(10-17)}$. Use of different serum cut-off points for vitamin D deficiency and insufficiency is also another important factor contributing to the wide range of variation in prevalence ${ }^{(7)}$. Several studies in rural Bangladesh have reported the vitamin D status of children under 5 years to 10 years of age although there is a high prevalence of rickets among the children ${ }^{(13,18)}$. Another study found a high prevalence of severe deficiency $(<25 \mathrm{nmol} / \mathrm{l})$ among children under 2 years old with pneumonia and matched healthy controls $^{(14)}$.

There have been few empirical studies aimed at identifying risk factors for vitamin D deficiency among pre-school children in the Indian subcontinent and Bangladesh $^{(12,14-16,19,20)}$. Studies conducted among other child populations have identified age, reduced intake of vitamin D-enriched foods, low sunshine exposure, skin covering, skin pigmentation, ethnicity, maternal vitamin D status, household crowding and air pollution as risk factors for vitamin D deficiency and insufficiency ${ }^{(12,15,16,21-28)}$. A study from rural Bangladesh among children aged under 2 years found that vitamin D-deficient children were more likely to live in households of lower socio-economic status and were more stunted than vitamin D-sufficient children ${ }^{(14)}$. However, a study in Pakistani infants found significantly lower vitamin D concentration among children from upper socioeconomic strata and among infants of educated mothers ${ }^{(19)}$. Thus, risk indicators for vitamin D deficiency need to be explored more carefully among children under 2 years of age.

The important role of vitamin $\mathrm{D}$ in health and disease has led to increased interest in measuring vitamin D status among children under 2 years old. There is a lack of evidence about the prevalence of vitamin D deficiency in children under 2 years of age in Bangladesh. Most of the studies in Bangladesh reported prevalence of vitamin D deficiency from rural areas. We were unable to identify studies reporting vitamin D deficiency among urban Bangladeshi children or what risk factors are associated with deficiency and insufficiency. Additionally, most of the studies did not consider nutritional status, which may play role in the prevalence rate as well as risk factors for insufficiency and deficiency among children under 2 years old. In the present study we aimed to determine the prevalence of vitamin D insufficiency and deficiency among 6-24-month-old underweight and normal-weight urban slum children as well as examine the socio-economic and dietary risk indicators for vitamin D deficiency and insufficiency among these children.

\section{Methods}

\section{Study design, setting and participants}

We used data from the Bangladesh component of the Malnutrition \& Enteric Diseases (MAL-ED) consortium $^{(29)}$, which is a multisite research project concerned with malnutrition and diarrhoeal diseases in early childhood. One of the components of the MAL-ED study was an intervention study carried out at the urban Mirpur field site in Dhaka. The coordinates of Mirpur are $23.8042^{\circ} \mathrm{N}$, $90 \cdot 3667^{\circ} \mathrm{E}$. Children aged 6-24 months with severe to moderate underweight (weight-for-age $Z$-score $<-2 \cdot 00$ ) were selected as cases for enrolment in the study through biannual household demographic surveillance of the community. Controls were well-nourished, normal-weight children (weight-for-age $Z$-score $\geq-1 \cdot 00$ ) matched for area of residence only. Details of the study design and site have been reported elsewhere ${ }^{(30)}$. Five hundred cases and 480 controls were enrolled during the period of November 2009 to February 2012. Children were assigned to receive one of two different intervention packages according to their nutritional status (underweight or normal weight) for 5 months while enrolled in the study. To achieve our proposed objectives, only the baseline data from the cross-sectional study design were analysed. Thus intervention packages and follow-up procedures are not described herein.

\section{Data collection}

Trained field workers collected household socioeconomic information and qualitative dietary intake information from mothers through a structured questionnaire at the time of enrolment. Demographic and Health Survey (DHS) questionnaires on household socioeconomic and demographic status were adapted for data collection $^{(31)}$. Similarly, dietary intake data were also collected using an FFQ based upon the DHS questionnaires which had previously been adapted (local names for common examples of the food items) and field tested by our team prior to data collection ${ }^{(31)}$. Field staff received standard training for data and sample collection before the implementation of the study at the field site. Trained field workers measured children's weight using a digital baby or toddler scale (Seca 354) at the time of enrolment and on a monthly basis throughout the enrolment period. Biannual refresher training courses were also conducted for quality assurance of data collection.

\section{Laboratory procedure}

A $5 \mathrm{ml}$ sample of venous blood was collected from each child at the time of enrolment. Samples were collected in trace-element-free containers for micronutrient assay. All assays for micronutrients, including vitamin $\mathrm{D}$, were performed at the nutritional biochemistry laboratory of the International Centre for Diarrheal Disease Research, Bangladesh (icddr,b). Serum vitamin D was measured using the IDS 25-Hydroxy Vitamin D EIA (enzyme immunoassay) Kit ${ }^{(32)}$ (IDS Ltd, Boldon, UK). Two levels of controls (REF AC-5705A, AC-5705B) were included in each kit. These two controls were run in each plate/run for monitoring accuracy and precision. The $\mathrm{CV}$ was 
$3 \cdot 8-11 \cdot 8 \%$ for control 1 and $5 \cdot 2-10 \cdot 7 \%$ for control 2 . Serum retinol was measured using the HPLC method described elsewhere ${ }^{(33)}$. Serum/plasma Zn concentration was determined using an air-acetylene flame atomic absorption spectrophotometer at $213.9 \mathrm{~nm}$ following dilution of the sample twelve times with deionized water. Accuracy and precision of analyses were ensured by using a bi-level serum trace element control provided by UTAK Laboratories Inc. (Valencia, CA, USA).

\section{Sample size and measurements}

The study profile is described in Fig. 1. Complete data of 468 underweight and 445 normal-weight children were available for the final analysis. The primary outcome of the study is the prevalence of vitamin D insufficiency and deficiency among 6-24-month-old children. Serum vitamin D was recoded using standard serum cut-off points: severe deficiency $(<25 \mathrm{nmol} / \mathrm{l})$, deficiency (25-49.99 nmol/1), insufficiency $(50-74.99 \mathrm{nmol} / \mathrm{l})$ and sufficiency $(\geq 75 \mathrm{nmol} / \mathrm{l})$. The available exposure variables comprised personal characteristics, measures of socioeconomic status, environmental factors, seasonality, and vitamin A and Zn status. A household asset index was constructed from the household asset information with principal component analysis as described for the DHS ${ }^{(34)}$. The UV index is usually high in Dhaka during April to September and lowest from November to January ${ }^{(35)}$. As UV-B radiation is essential for synthesis of vitamin D in human skin, four seasons, i.e. summer (May to July), autumn (August to October), winter (November to January) and spring (February to April), were created from the date of blood sample collection to measure the seasonal variation. Child's age $(6-11,12-17$ and 18-24 months), maternal education (illiterate, $1-5$ years and $\geq 6$ years of institutional education) and other relevant variables were created with recoding of information in the database. Vitamin A deficiency was defined as serum retinol level of $<0.7 \mu \mathrm{mol} / \mathrm{l}^{(36)}$ and serum $\mathrm{Zn}$ deficiency was defined as serum $\mathrm{Zn}$ level of $<9.9 \mu \mathrm{mol} / \mathrm{l}$ in pre-school children ${ }^{(37)}$.

\section{Statistical analysis}

Socio-economic and demographic variables, qualitative dietary intake, and vitamin $\mathrm{A}$ and $\mathrm{Zn}$ status were compared among individuals with vitamin D sufficiency, insufficiency and deficiency using ANOVA for continuous variables and the $\chi^{2}$ test of independence for categorical variables. For multivariable analyses, we combined both severe deficiency and deficiency into one category of deficient status $(<50 \mathrm{nmol} / \mathrm{l})$ to increase the statistical precision. A probability of less than 0.05 was considered a statistically significant association. Strength of association was measured by the estimating odds ratio and 95\% confidence interval. Multinomial logistic regression was used to estimate the odds of being vitamin D deficient or insufficient with the reference being vitamin D sufficient. Analyses were then done separately for underweight and normal-weight children. The variables that were statistically significant in the univariate analysis or deemed physiologically important factors or reported risk indicators in published literature were subsequently included in multivariable models to determine their independent

1129 children were eligible for enrolment

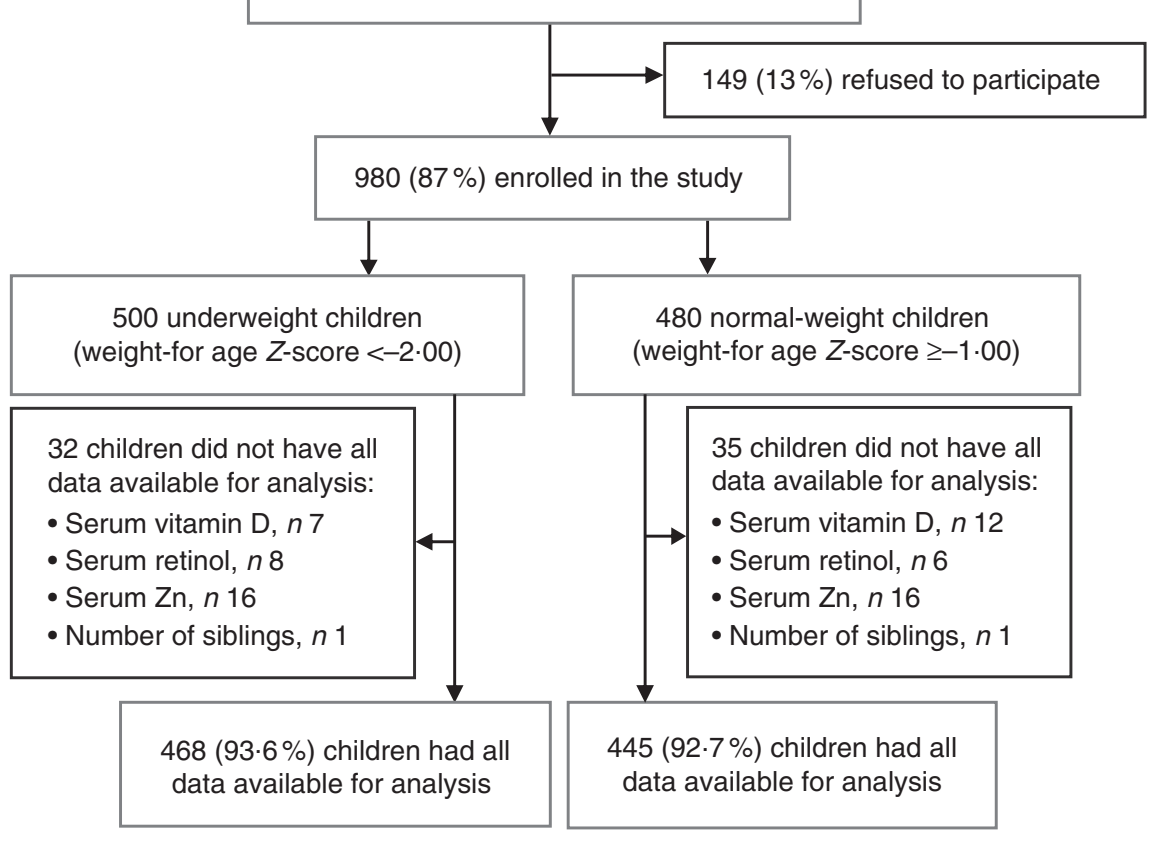

Fig. 1 Study profile 
association with the outcome variable. Analyses were carried out using the statistical software package STATA version $12 \cdot 0$.

\section{Ethical considerations}

The study (proposal \# 2008-020) was approved by the Research Review Committee and the Ethical Review Committee of icddr,b. Informed voluntary written consent was obtained from the parents or guardian for the participation of their child in the study. Parents or caregivers were assured about the non-disclosure of information collected from them, and were also informed about the use of data for analysis and use of results for improving health and nutritional care activities as well as publication, without disclosing the name or identity of their children.

\section{Results}

\section{Vitamin D status}

Vitamin D status of underweight and normal-weight children is presented in Table 1 . The median (interquartile range) vitamin $\mathrm{D}$ concentration was 57.5 (45.7-73.6) $\mathrm{nmol} / 1$ among underweight children and 51.8 (39.9-65.9) nmol/1 among normal-weight children. Only $23.1 \%$ of underweight children and $14.8 \%$ of normal-weight children were vitamin D sufficient.

\section{Factors associated with vitamin D status in underweight children}

In the unadjusted analysis, compared with being serum vitamin D sufficient, the odds of being serum vitamin D deficient were significantly increased among underweight children aged 12-17 and 18-24 months compared with children 6-11 months of age (Table 2). Similarly, underweight children were at a significantly higher risk of vitamin D deficiency during winter and spring compared with summer. Underweight children who did not consume any animal protein in last $24 \mathrm{~h}$ had $40 \%$ lower risk of vitamin D deficiency than children who consumed animal protein. There was a $50 \%$ lower risk of vitamin D deficiency among the underweight children who were serum $\mathrm{Zn}$ sufficient than in those who were serum $\mathrm{Zn}$ deficient.

In the adjusted model, compared with being serum vitamin D sufficient, children who were $\geq 18$ months of age were found to have a significantly greater risk of being vitamin $\mathrm{D}$ deficient than the younger group (6-11 months). Similarly, children had 3.0 times greater risk of vitamin $\mathrm{D}$ deficiency in winter than in summer. Likewise, in spring the risk increased up to 6.9 times compared with summer (Table 2). The probability of being vitamin $\mathrm{D}$ sufficient or insufficient among the underweight children was lowest during the spring time. On the other hand, the probability of being vitamin D deficient was highest among the underweight children during winter and spring (Fig. 2). Children whose mothers had $\geq 6$ years of institutional education were found to be at $2 \cdot 2$ times greater risk of vitamin D deficiency and $2 \cdot 6$ times greater risk of vitamin D insufficiency than the children of illiterate mothers. Children whose mothers had $1-5$ years of institutional education were found to be at 1.9 times greater risk of vitamin $\mathrm{D}$ insufficiency $v$. vitamin $\mathrm{D}$ sufficiency than the children of illiterate mothers after adjustment for other variables (Table 2).

\section{Factors associated with vitamin D status in normal-weight children}

Compared with being serum vitamin D sufficient, the risk of being serum vitamin D insufficient was greater among normal-weight children aged 18-24 months than among 6-11-month-old children in the unadjusted analysis (Table 3). However, there was no association of season with vitamin D insufficiency or deficiency found in the unadjusted analyses. Normal-weight children whose mothers had $\geq 6$ years of institutional education were found to have approximately threefold greater risk of vitamin D deficiency compared with illiterate mothers' children. A similar result was found with children who were from the highest quintile of the household wealth index compared with those from the lowest quintile.

Table 1 Serum vitamin D status among 6-24-month-old underweight and normal-weight children living in an urban slum of Dhaka, Bangladesh, November 2009-February 2012

\begin{tabular}{|c|c|c|c|c|}
\hline & \multicolumn{2}{|c|}{ Underweight children (WAZ $<-2.00 ; n$ 468) } & \multicolumn{2}{|c|}{ Normal-weight children (WAZ $\geq-1.00 ; n$ 445) } \\
\hline & Mean, median or $\%$ & SD, IQR or $n$ & Mean, median or $\%$ & $\mathrm{SD}, \mathrm{IQR}$ or $n$ \\
\hline \multicolumn{5}{|l|}{ Serum vitamin D (nmol/l) } \\
\hline Mean and SD & $60 \cdot 6$ & 23.2 & $54 \cdot 1$ & 20.8 \\
\hline Median and IQR & 57.5 & $45 \cdot 7-73 \cdot 6$ & $51 \cdot 8$ & $39.9-65.9$ \\
\hline Range & \multicolumn{2}{|c|}{$12 \cdot 3-188 \cdot 9$} & \multicolumn{2}{|c|}{$10 \cdot 6-188 \cdot 7$} \\
\hline \multicolumn{5}{|l|}{ Serum vitamin D status, $\%$ and $n$} \\
\hline Sufficient $(\geq 75 \mathrm{nmol} / \mathrm{l})$ & $23 \cdot 1$ & 108 & $14 \cdot 8$ & 66 \\
\hline Insufficient $(50-74.99 \mathrm{nmol} / \mathrm{l})$ & $42 \cdot 3$ & 198 & $39 \cdot 6$ & 176 \\
\hline Deficient $(25-49.99 \mathrm{nmol} / \mathrm{l})$ & $31 \cdot 2$ & 146 & $40 \cdot 0$ & 178 \\
\hline Severely deficient $(<25 \mathrm{nmol} / \mathrm{l})$ & 3.4 & 16 & $5 \cdot 6$ & 25 \\
\hline
\end{tabular}

WAZ, weight-for-age Z-score; IQR, interquartile range. 
Table 2 Characteristics and factors associated with vitamin D deficiency and insufficiency among 6-24-month-old underweight children living in an urban slum of Dhaka, Bangladesh, November 2009-February 2012; multinomial logistic regression analysis with sufficient serum vitamin D status as reference $(n 468)$

\begin{tabular}{|c|c|c|c|c|c|c|c|c|c|c|c|c|c|c|}
\hline \multirow[b]{4}{*}{ Indicator } & \multicolumn{14}{|c|}{ Serum vitamin D status } \\
\hline & & & & & & & & Insu & icient & & & Def & ient & \\
\hline & \multicolumn{2}{|c|}{ Sufficient } & \multicolumn{2}{|c|}{ Insufficient } & \multicolumn{2}{|c|}{ Deficient } & \multicolumn{2}{|c|}{ Unadjusted } & \multicolumn{2}{|c|}{ Adjusted $†$} & \multicolumn{2}{|c|}{ Unadjusted } & \multicolumn{2}{|c|}{ Adjusted $†$} \\
\hline & $\%$ & $n$ & $\%$ & $n$ & $\%$ & $n$ & OR & $95 \% \mathrm{Cl}$ & OR & $95 \% \mathrm{Cl}$ & OR & $95 \% \mathrm{Cl}$ & OR & $95 \% \mathrm{Cl}$ \\
\hline \multicolumn{15}{|l|}{ Age group (months) $\ddagger$} \\
\hline $12-17$ & $27 \cdot 8$ & 30 & 30.8 & 61 & 34.6 & 56 & 1.3 & $0.8,2 \cdot 3$ & $1 \cdot 1$ & $0.6,2.1$ & $2 \cdot 2^{*}$ & $1 \cdot 2,4 \cdot 1$ & 1.7 & $0.9,3.4$ \\
\hline $18-24$ & $23 \cdot 1$ & 25 & $29 \cdot 3$ & 58 & $38 \cdot 3$ & 62 & 1.5 & $0.9,2.8$ & 1.4 & $0.7,2.6$ & $3.0^{*}$ & $1 \cdot 6,5.5$ & $2 \cdot 9^{*}$ & $1 \cdot 5,5 \cdot 7$ \\
\hline Femaleł & 43.5 & 47 & $49 \cdot 0$ & 97 & 53.7 & 87 & 1.2 & $0.8,2.0$ & $1 \cdot 3$ & $0 \cdot 8,2 \cdot 1$ & 1.5 & $0.9,2.4$ & 1.6 & $0.9,2 \cdot 7$ \\
\hline \multicolumn{15}{|l|}{ Season of vitamin D measurement‡ } \\
\hline Autumn & $28 \cdot 7$ & 31 & $22 \cdot 2$ & 44 & 11.7 & 19 & $1 \cdot 1$ & $0.5,2.1$ & $1 \cdot 0$ & $0.5,2 \cdot 1$ & $1 \cdot 0$ & $0.4,2 \cdot 2$ & 0.9 & $0.4,2 \cdot 3$ \\
\hline Winter & $29 \cdot 6$ & 32 & $40 \cdot 4$ & 80 & $38 \cdot 3$ & 62 & 1.9 & $1 \cdot 0,3 \cdot 6$ & $1 \cdot 8$ & $0.9,3.4$ & $3.0^{*}$ & $1.5,6.4$ & $3.0^{*}$ & $1 \cdot 4,6 \cdot 4$ \\
\hline Spring & 14.7 & 16 & $18 \cdot 2$ & 36 & 38.9 & 63 & 1.7 & $0.8,3.7$ & 1.6 & $0.7,3.5$ & $6 \cdot 3^{*}$ & $2 \cdot 8,14 \cdot 2$ & $6 \cdot 9^{*}$ & $3 \cdot 0,16 \cdot 1$ \\
\hline More than one sibling $\ddagger$ & $58 \cdot 3$ & 63 & $64 \cdot 1$ & 127 & 53.7 & 87 & 1.3 & $0 \cdot 8,2 \cdot 1$ & 1.4 & $0.8,2 \cdot 4$ & 0.8 & $0.5,1.3$ & 0.8 & $0.5,1.4$ \\
\hline Family size $>5$ family members $\ddagger$ & $25 \cdot 0$ & 27 & $30 \cdot 3$ & 60 & $22 \cdot 8$ & 37 & 1.3 & $0 \cdot 8,2 \cdot 2$ & 1.4 & $0 \cdot 8,2 \cdot 5$ & 0.9 & $0.5,1.6$ & 0.9 & $0.5,1 \cdot 7$ \\
\hline \multicolumn{15}{|l|}{ Mother's education $\ddagger$} \\
\hline $1-5$ years & $45 \cdot 4$ & 49 & $50 \cdot 0$ & 99 & $40 \cdot 7$ & 66 & 1.6 & $0.9,2.8$ & $1.9^{*}$ & $1 \cdot 0,3 \cdot 6$ & $1 \cdot 1$ & $0 \cdot 6,2 \cdot 0$ & $1 \cdot 1$ & $0 \cdot 6,2 \cdot 2$ \\
\hline \multirow{2}{*}{\multicolumn{15}{|c|}{ Household wealth index $\ddagger$}} \\
\hline & & & & & & & & & & & & & & \\
\hline Second quintile & $21 \cdot 3$ & 23 & 23.7 & 47 & 23.5 & 38 & $1 \cdot 1$ & $0 \cdot 6,2 \cdot 1$ & $1 \cdot 0$ & $0.5,2.0$ & $1 \cdot 0$ & $0.5,2.0$ & $1 \cdot 0$ & $0.5,2 \cdot 1$ \\
\hline Middle quintile & $22 \cdot 2$ & 24 & 20.2 & 40 & 17.9 & 29 & 0.9 & $0.5,1.8$ & 0.7 & $0.3,1.4$ & 0.7 & $0.4,1.5$ & 0.6 & $0.3,1.4$ \\
\hline Fourth quintile & 13.9 & 15 & $18 \cdot 2$ & 36 & 18.5 & 30 & $1 \cdot 3$ & $0.6,2 \cdot 7$ & 0.9 & $0.4,2 \cdot 1$ & $1 \cdot 2$ & $0.6,2.6$ & $1 \cdot 1$ & $0.5,2.9$ \\
\hline Highest quintile & 13.9 & 15 & 9.1 & 18 & 8.6 & 14 & 0.6 & $0.3,1.5$ & 0.4 & $0.1,0.98$ & 0.6 & $0.2,1.3$ & 0.4 & $0.1,1 \cdot 2$ \\
\hline Did not drink any animal or powdered milk in last $24 \mathrm{~h} \ddagger$ & $63 \cdot 0$ & 68 & 68.2 & 135 & $72 \cdot 8$ & 118 & 1.3 & $0.8,2 \cdot 1$ & 1.2 & $0.7,2.0$ & 1.6 & $0.9,2.7$ & 1.3 & $0.7,2 \cdot 3$ \\
\hline Did not consume any animal protein in last $24 \mathrm{~h} \ddagger$ & $55 \cdot 6$ & 60 & 47.0 & 95 & $42 \cdot 0$ & 68 & 0.7 & $0.5,1.2$ & 0.8 & $0.5,1.3$ & $0.6^{*}$ & $0.4,0.9$ & 0.7 & $0.4,1 \cdot 2$ \\
\hline Serum retinol mild deficiency or normal status $(\geq 0.7 \mu \mathrm{mol} / /) \ddagger$ & $64 \cdot 8$ & 70 & $58 \cdot 1$ & 115 & $56 \cdot 8$ & 92 & 0.7 & $0.5,1.2$ & & $\mathrm{x}$ & 0.7 & $0.4,1.2$ & & $\mathrm{x}$ \\
\hline Serum Zn sufficiency $(\geq 9.9 \mu \mathrm{mol} / /) \ddagger$ & $85 \cdot 2$ & 92 & $82 \cdot 3$ & 163 & 74.1 & 120 & 0.8 & $0.4,1.5$ & & $\mathrm{x}$ & $0.5^{\star}$ & $0.3,0.9$ & & $\mathrm{x}$ \\
\hline
\end{tabular}

\section{${ }^{\star} P<0.05$.}

†Adjusted for child age group, child sex, season of vitamin D measurement, number of siblings, family size, mother's education, household wealth index, consumption of any diary product and animal protein.

†Reference values for independent variables: $6-11$ months; male; summer; number of siblings $\leq 1$, illiterate mother; family size $\leq 5$ members, lowest asset quintile; consumption of animal or powered milk; consumption of any animal protein; serum retinol moderate to severe deficiency; and serum Zn deficiency. 

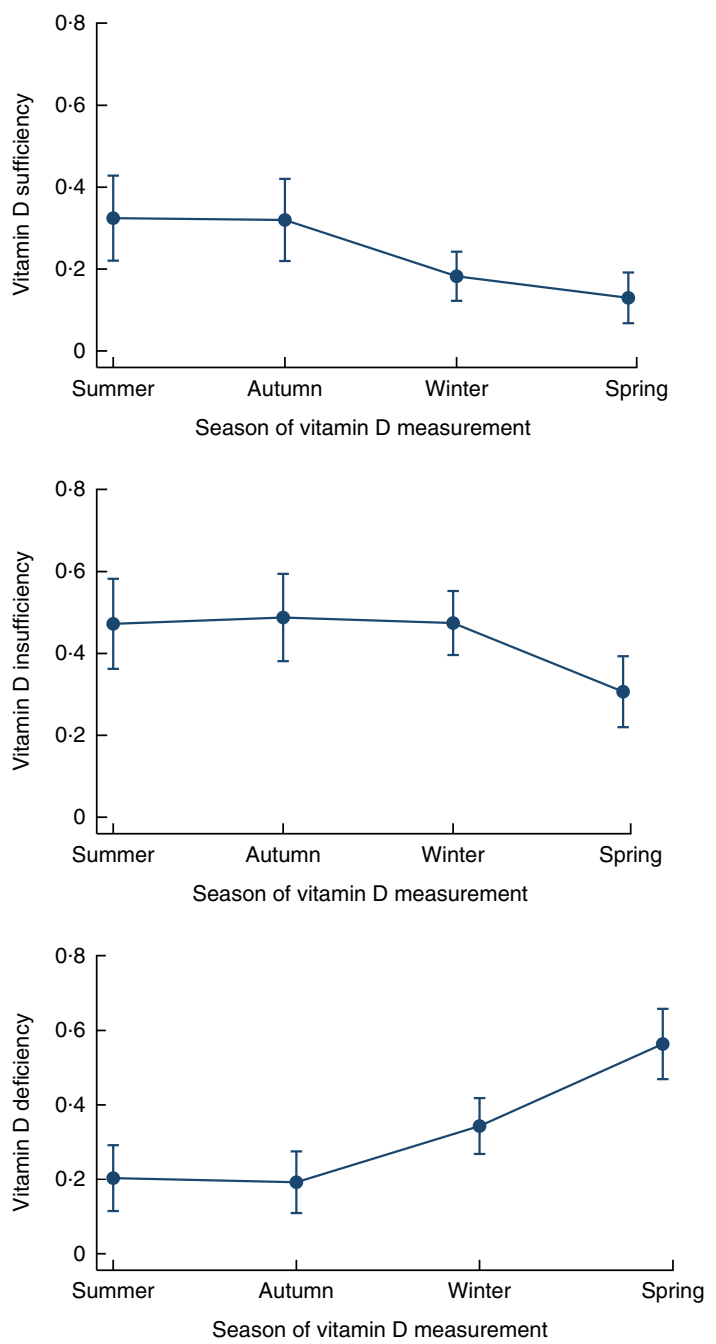

Fig. 2 Adjusted predictions of vitamin D sufficiency, insufficiency and deficiency by season, with $95 \% \mathrm{Cl}$ indicated by vertical bars, among underweight children living in an urban slum of Dhaka, Bangladesh, November 2009-February 2012

There was respectively 2.4 and 2.2 times greater risk of vitamin D insufficiency and deficiency, compared with vitamin D sufficiency, among normal-weight children with serum Zn sufficiency than among normal-weight children with serum $\mathrm{Zn}$ insufficiency (Table 3).

In the adjusted model, compared with being serum vitamin D sufficient, children aged 18-24 months were found to be 3.6 times more vitamin $D$ insufficient than the younger age group (6-11 months old). Autumn was found to be associated with a significantly lower risk of vitamin D insufficiency among children than the summer months. Winter and spring were not associated with either deficiency or insufficiency of serum vitamin D status among the normal-weight children (Table 3). Among the normal-weight children the probabilities of vitamin D deficiency and insufficiency were high (40-50\%) even during the summer (Fig. 3). Maternal education was not associated with vitamin D deficiency or insufficiency after adjusting for other variables. On the other hand, normalweight children from the richest quintile were 3.7 times more likely to be vitamin $\mathrm{D}$ insufficient $v$. vitamin $\mathrm{D}$ sufficient than those in the lower quintile of the household wealth index (Table 3).

A detailed description of the consumption of vitamin D-rich foods in the last $24 \mathrm{~h}$ by vitamin D status among underweight and normal-weight children is presented in Table 4 .

\section{Discussion}

We have found remarkable prevalence of vitamin D insufficiency and deficiency among 6-24-month-old underweight as well as normal-weight children from an urban slum, indicating that vitamin D insufficiency and deficiency are important health problems especially among young children living in Bangladesh. Importantly, the factors associated with vitamin D insufficiency and deficiency were different between normal-weight children and underweight children.

One of the important drawbacks of available studies reporting prevalence of vitamin D status is the use of different cut-off levels by researchers. Most clinicians define vitamin D deficiency using a cut-off point of serum vitamin $\mathrm{D}<25 \mathrm{nmol} / \mathrm{l}$, which is the cut-off point associated with the occurrence of rickets and osteomalacia ${ }^{(38,39)}$. One study has proposed a cut-off point of $>50 \mathrm{nmol} / \mathrm{l}$ for optimal bone mineral density, bone turnover and muscle strength, while a cut-off point of $>75 \mathrm{nmol} / \mathrm{l}$ for maintaining an adequate immune response has been proposed by another ${ }^{(40,41)}$. The difference in these recommendations may reflect the different actions of vitamin $D$ in physiological processes. Regardless of the different cut-off levels used for reporting status of serum vitamin $\mathrm{D}$, all studies $^{(13-15,18)}$ including our study showed a significant burden of vitamin D deficiency and insufficiency among children under 2 years old in Bangladesh.

The tropical geographical location of Bangladesh means that vitamin D synthesis is possible year-round due to the intense UV-B radiation in the country compared with other zones of the globe ${ }^{(35)}$. Our study shows that despite geographical setting, vitamin D insufficiency and deficiency is quite prevalent in Bangladeshi children 6-24 months of age. Our study demonstrates that this is a significant issue in normal-weight children since it has reported a high prevalence of vitamin $\mathrm{D}$ insufficiency and deficiency among 6-24-month-old normal-weight children. Studies carried out in Chakaria, Coxesbazar found that $11 \%$ of children had active rickets and that vitamin D deficiency ranged from 6 to $21 \%$ among the children under 5 years old in that community ${ }^{(18,20)}$. Additionally a study from same area reported that only $6 \%$ of children (ten out of 158 participants) were suffering from severe vitamin D deficiency ${ }^{(13)}$, which supports our 
Table 3 Characteristics and factors associated with vitamin D deficiency and insufficiency among 6-24-month-old normal-weight children living in an urban slum of Dhaka, Bangladesh, November 2009-February 2012; multinomial logistic regression analysis with sufficient serum vitamin D status as reference $(n 445)$

\begin{tabular}{|c|c|c|c|c|c|c|c|c|c|c|c|c|c|c|}
\hline \multirow[b]{4}{*}{ Indicator } & \multicolumn{14}{|c|}{ Serum vitamin $D$ status } \\
\hline & & & \multirow{2}{*}{\multicolumn{2}{|c|}{ Insufficient }} & \multirow{2}{*}{\multicolumn{2}{|c|}{ Deficient }} & \multicolumn{4}{|c|}{ Insufficient } & \multicolumn{4}{|c|}{ Deficient } \\
\hline & \multicolumn{2}{|c|}{ Sufficient } & & & & & \multicolumn{2}{|c|}{ Unadjusted } & \multicolumn{2}{|c|}{ Adjusted $\dagger$} & \multicolumn{2}{|c|}{ Unadjusted } & \multicolumn{2}{|c|}{ Adjusted $†$} \\
\hline & $\%$ & $n$ & $\%$ & $n$ & $\%$ & $n$ & OR & $95 \% \mathrm{Cl}$ & OR & $95 \% \mathrm{Cl}$ & OR & $95 \% \mathrm{Cl}$ & OR & $95 \% \mathrm{Cl}$ \\
\hline \multicolumn{15}{|l|}{ Age group (months) $(P=0.055) \ddagger$} \\
\hline $12-17$ & $25 \cdot 8$ & 17 & $27 \cdot 8$ & 49 & 31.5 & 64 & 1.4 & $0.7,2.8$ & 1.2 & $0.6,2.5$ & 1.5 & $0.8,2.9$ & $1 \cdot 1$ & $0.5,2.2$ \\
\hline $18-24$ & $7 \cdot 6$ & 5 & $22 \cdot 2$ & 39 & $15 \cdot 8$ & 32 & $3.9^{*}$ & $1.4,10.6$ & $3 \cdot 6^{*}$ & $1 \cdot 2,10 \cdot 6$ & 2.6 & $0.96,7.2$ & $2 \cdot 2$ & $0.8,6.4$ \\
\hline Female $\neq$ & $47 \cdot 0$ & 31 & $50 \cdot \overline{6}$ & 89 & $47 \cdot 3$ & 96 & 1.1 & $0.6-2.0$ & 1.3 & $0 \cdot 7,2 \cdot 4$ & 1.0 & $0.6-1.8$ & $1 \cdot 1$ & $0.6,1.9$ \\
\hline \multicolumn{15}{|l|}{ Season of vitamin D measurementł } \\
\hline Autumn & $25 \cdot 8$ & 17 & $14 \cdot 8$ & 26 & $12 \cdot 3$ & 25 & 0.5 & $0.2,1 \cdot 2$ & $0.4^{*}$ & $0.1,0.9$ & 0.5 & $0.2,1 \cdot 3$ & 0.4 & $0.2,1 \cdot 1$ \\
\hline Winter & 31.8 & 21 & 43.2 & 76 & $42 \cdot 9$ & 87 & $1 \cdot 1$ & $0.5,2.5$ & 1.0 & $0.4,2.4$ & 1.4 & $0.6,3.3$ & 1.3 & $0.5,3.2$ \\
\hline Spring & $25 \cdot 8$ & 17 & 21.6 & 38 & 29.1 & 59 & 0.7 & $0.3,1.6$ & 0.6 & $0.2,1.5$ & $1 \cdot 2$ & $0.5,2.8$ & 1.1 & $0.5,2 \cdot 8$ \\
\hline More than one sibling $\ddagger$ & $66 \cdot 7$ & 44 & $60 \cdot 2$ & 106 & $62 \cdot 1$ & 126 & 0.8 & $0.4,1.4$ & 0.6 & $0.3,1.2$ & 0.8 & $0.4,1.5$ & 0.8 & $0.4,1.5$ \\
\hline Family size $>5$ family members $\ddagger$ & $27 \cdot 3$ & 18 & 23.3 & 41 & $22 \cdot 2$ & 45 & 0.8 & $0.4,1.5$ & 0.6 & $0.3,1.3$ & 0.8 & $0.4,1.4$ & 0.6 & $0.3,1.3$ \\
\hline \multicolumn{15}{|l|}{ Mother's education $\ddagger$} \\
\hline $1-5$ years & 51.5 & 34 & 43.7 & 77 & 38.9 & 79 & $1 \cdot 1$ & $0.5,2.4$ & 0.8 & $0.4,1.9$ & $1 \cdot 2$ & $0 \cdot 6,2 \cdot 7$ & $1 \cdot 1$ & $0.5,2.5$ \\
\hline$\geq 6$ years & $27 \cdot 3$ & 18 & $40 \cdot 3$ & 71 & $48 \cdot 3$ & 98 & $2 \cdot 0$ & $0.9,4.5$ & 1.0 & $0.4,2.8$ & $2 \cdot 9^{*}$ & $1 \cdot 3,6 \cdot 7$ & $2 \cdot 1$ & $0.8,5.5$ \\
\hline \multicolumn{15}{|l|}{ Household wealth index $\ddagger$} \\
\hline Second quintile & $19 \cdot 7$ & 13 & $15 \cdot 3$ & 27 & $17 \cdot 2$ & 35 & 1.0 & $0.4,2.9$ & $1 \cdot 2$ & $0.4,3.8$ & $1 \cdot 3$ & $0.5,3.7$ & 1.3 & $0.4,4.0$ \\
\hline Middle quintile & 28.8 & 19 & $14 \cdot 8$ & 26 & 21.2 & 43 & 0.7 & $0.2,1.8$ & 0.8 & $0.3,2.3$ & $1 \cdot 1$ & $0.4,3.0$ & 1.2 & $0.4,3.3$ \\
\hline Fourth quintile & $21 \cdot 2$ & 14 & $26 \cdot 1$ & 46 & $21 \cdot 2$ & 43 & 1.6 & $0.6,4.5$ & $2 \cdot 0$ & $0.7,6.1$ & 1.5 & $0.6,4 \cdot 2$ & 1.4 & $0.5,4.4$ \\
\hline Highest quintile & $16 \cdot 7$ & 11 & 33.5 & 59 & 31.5 & 64 & 2.7 & $0.9,7.5$ & $3.7^{\star}$ & $1 \cdot 1,12 \cdot 5$ & $2 \cdot 9^{*}$ & $1.0,8 \cdot 1$ & $2 \cdot 7$ & $0.8,8.8$ \\
\hline Did not drink any animal or powdered milk in last $24 \mathrm{~h} \ddagger$ & $47 \cdot 0$ & 31 & $55 \cdot 0$ & 97 & $56 \cdot 2$ & 114 & 1.4 & $0.8,2.4$ & 1.6 & $0.9,3.1$ & 1.4 & $0.8,2.5$ & 1.7 & $0.9,3.1$ \\
\hline Did not consume any animal protein in last $24 \mathrm{~h} \ddagger$ & $60 \cdot 6$ & 40 & $51 \cdot 7$ & 91 & $48 \cdot 8$ & 99 & 0.7 & $0.4,1 \cdot 2$ & 1.0 & $0.5,2.0$ & 0.6 & $0.3,1 \cdot 1$ & 0.9 & $0.5,1.6$ \\
\hline Serum retinol mild deficiency or normal status $(\geq 0.7 \mu \mathrm{mol} / /) \ddagger$ & 68.2 & 45 & 67.0 & 118 & $64 \cdot 0$ & 130 & 0.9 & $0.5,1.7$ & & $x$ & 0.8 & $0.5,1.5$ & & $\mathrm{x}$ \\
\hline Serum Zn sufficiency $(\geq 9.9 \mu \mathrm{mol} / \mathrm{l}) \ddagger$ & $72 \cdot 7$ & 48 & $86 \cdot 4$ & 152 & $85 \cdot 2$ & 173 & $2 \cdot 4^{*}$ & $1 \cdot 2,4.7$ & & $\mathrm{x}$ & $2 \cdot 2^{*}$ & $1 \cdot 1,4 \cdot 2$ & & $\mathrm{x}$ \\
\hline
\end{tabular}

\section{${ }^{*} P<0.05$.}

†Adjusted for child age group, child sex, season of vitamin D measurement, number of siblings, family size, mother's education, household wealth index, consumption of any diary product and animal protein

fReference values for independent variables: $6-11$ months; male; summer; number of siblings $\leq 1$, illiterate mother; family size $\leq 5$ members, lowest asset quintile; consumption of animal or powered milk; consumption of any animal protein; serum retinol moderate to severe deficiency; and serum Zn deficiency. 

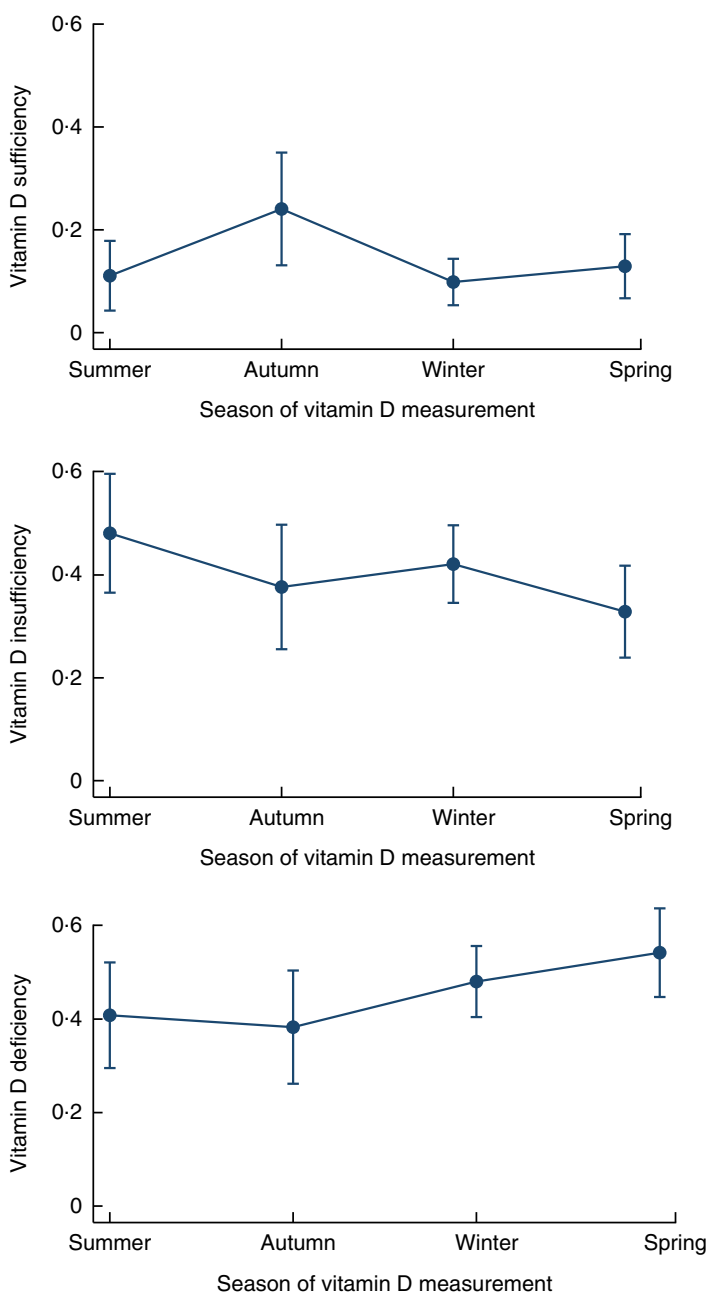

Fig. 3 Adjusted predictions of vitamin D sufficiency, insufficiency and deficiency by season, with $95 \% \mathrm{Cl}$ indicated by vertical bars, among normal-weight children living in an urban slum of Dhaka, Bangladesh, November 2009-February 2012

finding (Table 1). Recently a case-control study ${ }^{(15)}$ was carried out among 1-24-month-old children of northeastern rural Bangladesh and found that $32 \%$ of all children (including cases and controls) were severely vitamin D deficient $(<25 \mathrm{nmol} / \mathrm{l})$, with $70 \%$ having serum vitamin D less than $40 \mathrm{nmol} / \mathrm{l}$. However, that study was conducted during the winter season (January-February) when children had a significant risk of severe deficiency of vitamin D. Unreported results of our study also correlate with the finding of high prevalence of severe deficiency during winter and spring seasons.

Several studies from India also have demonstrated low serum vitamin D levels among pre-school children. A longitudinal study conducted among pregnant women found that 36 and $62 \%$ of neonates were vitamin $\mathrm{D}$ deficient or insufficient, respectively ${ }^{(12)}$. Another study in impoverished areas of Delhi, India found that the prevalence of low serum vitamin $\mathrm{D}$ status among children ranged from 2 to $84 \%$ but could not explain this wide

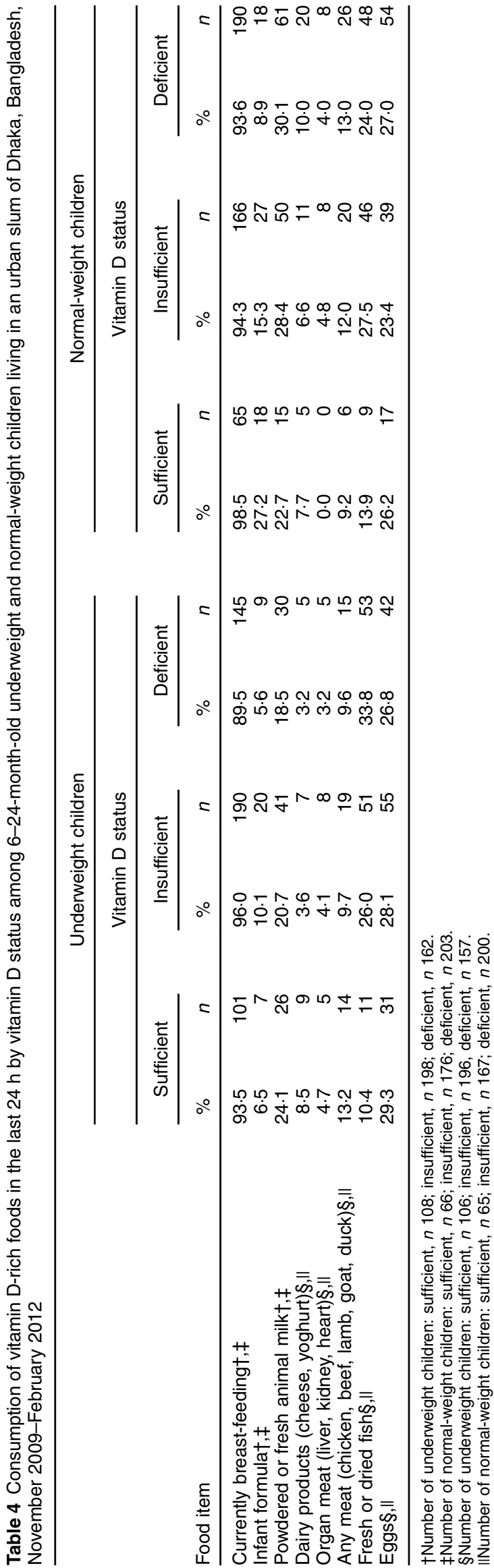


variation in prevalence ${ }^{(16)}$. In Karachi, Pakistan, severe vitamin D deficiency was found among $52 \%$ of healthy breast-fed infants ${ }^{(11)}$. Thus, our findings from urban Bangladesh in combination with earlier findings from infants in urban Pakistan and India demonstrate that there is remarkable vitamin D deficiency and insufficiency among young infants in South Asia and that a tropical climate with year-round adequate sunshine does not necessarily protect against low vitamin D status in the first 2 years of life. In regions such as Bangladesh, vitamin D levels can be low due to skin pigmentation ${ }^{(25,42)}$, air pollution (by preventing the penetration of UV-B radiation) ${ }^{(43)}$, clothing covering practices of children $^{(44)}$, less physical and outdoor activities, maternal vitamin $\mathrm{D}$ deficiency ${ }^{(45)}$, inadequate or very little intake of liver, eggs, dairy products, sea fish or fish oil (which are rich sources of vitamin D), and also the absence of any supplementary or fortification programme in this vulnerable population group.

Our study demonstrates that the vitamin D deficiency and insufficiency in young children increases with age, which is in agreement with previous studies ${ }^{(8,21,26)}$. The high level of vitamin $\mathrm{D}$ in our youngest age group can partially be explained by the consumption of dairy products and almost universal rate of breast-feeding during the younger childhood period compared with the older childhood period. Our underweight children had significant risk of vitamin D deficiency during winter and spring, which was also observed in the studies conducted among the general child population elsewhere $^{(7,9,10,12,16,21,22,24,46)}$. However in our study, autumn was found to be protective for vitamin D insufficiency in normal-weight children. The higher probabilities (40-50\%) of normal-weight children being vitamin D insufficient and deficient in summer could influence the results in later periods - autumn, winter and spring (Fig. 3). Perhaps for this reason autumn was found to be protective and no significant differences were seen in vitamin D deficiency or insufficiency during winter and spring among normal-weight children.

In our study, underweight children whose mothers had $\geq 6$ years of school instruction were significantly more vitamin D insufficient and deficient than children of illiterate mothers. Studies from Pakistan, Jordan and Saudi Arabia have reported similar findings in the general child population $^{(11,23,47)}$. Educated mothers may confine their infants indoors due to the polluted, congested and highly populated slum environment, which ultimately leads to reduced exposure to sunlight, and this could explain the high prevalence of vitamin D deficiency among them. Maternal education did not predict vitamin D deficiency in normal-weight children. In an unreported analysis of our study we found that mothers of normal-weight children are significantly more literate than underweight children's mothers. Homogeneity in the higher educational status of the mothers of normal-weight children probably plays a role in this finding among normal-weight children.
In our study we did not find any association between dietary intake of milk products or animal protein and vitamin D deficiency or insufficiency. Breast-fed infants are often at a greater risk of developing deficiency, which might be due to low vitamin D status of women of childbearing age ${ }^{(45,48)}$. However, we did not collect breast milk or blood samples from mothers for estimation of serum vitamin D status. Moreover, the breast-feeding rate was almost universal in our study participants; thus we are unable to explore the role of breast-feeding on serum vitamin D status.

Vitamin D and Zn both play important roles in human health and do not interact directly. Both play an important role in immune function. In our study we found a positive relationship between insufficient serum $\mathrm{Zn}$ status and deficient status of vitamin $\mathrm{D}$ in underweight children but an inverse relationship in normal-weight children in unadjusted analysis. A possible explanation for this finding is that underweight children were suffering from multiple micronutrient deficiencies ${ }^{(49,50)}$, especially coexisting serum $\mathrm{Zn}$ and vitamin $\mathrm{D}$ deficiencies.

\section{Limitations}

The results of the present study need to be interpreted in light of its limitations. First, we used data from the MAL-ED community-based study with prospective case-control design in an urban setting; results do not represent the general child population as well as the rural population. Second, the main source of vitamin D in man is exposure of bare skin to sunlight. We did not collect any information about the frequency and duration of sunlight exposure, clothing practices of children, cultural beliefs and outdoor activities of the children, which could be weaknesses of the study. Third, supporting information related to vitamin $\mathrm{D}$ and Ca homeostasis, such as serum intact parathyroid hormone levels, alkaline phosphatase, bone markers or bone parameters, which could add more strength to the study, was not measured.

\section{Conclusions}

The present study provides important information about the significant burden of vitamin D insufficiency and deficiency in both underweight and normal-weight children and associated risk factors in urban Bangladesh. Our study demonstrates that the risk factors for vitamin D deficiency and insufficiency differ between normal-weight and underweight children, and highlight the need for interventions, including nutritional education regarding spending time outdoors in sunshine for 10-16 min at least three or four times weekly and supplementation, to be tailored to the specific needs of particular subgroups. Importantly, the burden and risk factors of vitamin D deficiency in both underweight and normal-weight 6-24-month-old children identified in the study warrant 
the design and implementation of a vitamin D-specific health and nutritional programme in Bangladesh.

\section{Acknowledgements}

Financial support: The Etiology, Risk Factors and Interactions of Enteric Infections and Malnutrition and the Consequences for Child Health and Development Project (MAL-ED) is carried out as a collaborative project supported by the Bill \& Melinda Gates Foundation, the Foundation for the National Institutes of Health, and the National Institutes of Health, Fogarty International Center. The funders had no role in the design, analysis or writing of this article. Conflict of interest: None. Authorship: A.M.S.A., T.A., K.Z.L., R.J.S.M. and A.A.M. conceived and designed the study; A.M.S.A., T.A., M.M., M.M.I., M.I.H., S.M.A.G., A.S., R.H., R.L.G. and W.A.P. oversaw data collection; A.M.S.A., K.Z.L., R.J.S.M. and A.A.M. analysed the data; A.M.S.A., T.A., K.Z.L., R.J.S.M., M.M., M.M.I., M.I.H., S.M.A.G., A.S., R.H., R.L.G., W.A.P. and A.A.M. interpreted the data; A.M.S.A. drafted the manuscript; A.M.S.A., T.A., K.Z.L., R.J.S.M. and A.A.M. contributed to redrafting the manuscript. Ethics of human subject participation: The present analysis of data of children aged less than 2 years was part of a Bangladesh, MAL-ED Network study that aimed to understand burden of vitamin $\mathrm{D}$ deficiency and its predictors. The study (proposal \# 2008-020) was approved by the Research Review Committee and the Ethical Review Committee of icddr,b in 2008. The caregiver of eligible children provided informed written consent before collection of data and all biological samples at the time of enrolment. The written consent was documented by keeping a check mark in the questionnaire which was again shown to the parents. Parents or caregivers were assured about the non-disclosure of information collected from them, and were informed about the use of data for analysis and use of results for improving health and nutritional care activities as well as publication, without disclosing the name or identity of their children. The Ethical Review Committee of icddr,b was satisfied with the written participation, maintenance of all rights to participate in the study or to withdraw the child from the study at any time without depriving from usual services.

\section{References}

1. Holick MF (2007) Vitamin D deficiency. N Engl J Med 357 , 266-281.

2. Hewison M (2011) Vitamin D and innate and adaptive immunity. Vitam Horm 86, 23-62.

3. Hewison M (2012) Vitamin D and immune function: autocrine, paracrine or endocrine? Scand J Clin Lab Invest Suppl 243, 92-102.

4. Holick MF (2012) The D-lightful vitamin D for child health. JPEN J Parenter Enteral Nutr 36, 1 Suppl., 9S-19S.
5. Lucas RM, McMichael AJ, Armstrong BK et al. (2008) Estimating the global disease burden due to ultraviolet radiation exposure. Int J Epidemiol 37, 654-667.

6. Calvo MS, Whiting SJ \& Barton CN (2005) Vitamin D intake: a global perspective of current status. J Nutr 135, 310-316.

7. Arabi A, El Rassi R \& El-Hajj Fuleihan G (2010) Hypovitaminosis D in developing countries - prevalence, risk factors and outcomes. Nat Rev Endocrinol 6, 550-561.

8. Oren Y, Shapira Y, Agmon-Levin N et al. (2010) Vitamin D insufficiency in a sunny environment: a demographic and seasonal analysis. Isr Med Assoc J 12, 751-756.

9. van Schoor NM \& Lips P (2011) Worldwide vitamin D status. Best Pract Res Clin Endocrinol Metab 25, 671-680.

10. Agarwal KS, Mughal MZ, Upadhyay P et al. (2002) The impact of atmospheric pollution on vitamin D status of infants and toddlers in Delhi, India. Arch Dis Child 87, $111-113$

11. Atiq M, Suria A, Nizami SQ et al. (1998) Vitamin D status of breastfed Pakistani infants. Acta Paediatr 87, 737-740.

12. Bhalala U, Desai M, Parekh P et al. (2007) Subclinical hypovitaminosis D among exclusively breastfed young infants. Indian Pediatr 44, 897-901.

13. Combs GF Jr, Hassan N, Dellagana N et al. (2008) Apparent efficacy of food-based calcium supplementation in preventing rickets in Bangladesh. Biol Trace Elem Res 121, 193-204.

14. Roth DE, Shah MR, Black RE et al. (2010) Vitamin D status of infants in northeastern rural Bangladesh: preliminary observations and a review of potential determinants. J Health Popul Nutr 28, 458-469.

15. Roth DE, Shah R, Black RE et al. (2010) Vitamin D status and acute lower respiratory infection in early childhood in Sylhet, Bangladesh. Acta Paediatr 99, 389-393.

16. Tiwari L \& Puliyel JM (2004) Vitamin D level in slum children of Delhi. Indian Pediatr 41, 1076-1077.

17. Wayse V, Yousafzai A, Mogale K et al. (2004) Association of subclinical vitamin D deficiency with severe acute lower respiratory infection in Indian children under 5 y. Eur J Clin Nutr 58, 563-567.

18. Fischer PR, Rahman A, Cimma JP et al. (1999) Nutritional rickets without vitamin D deficiency in Bangladesh. $J$ Trop Pediatr 45, 291-293.

19. Atiq M, Suria A, Nizami SQ et al. (1998) Maternal vitamin-D deficiency in Pakistan. Acta Obstet Gynecol Scand 77, 970-973.

20. Combs GF \& Hassan N (2005) The Chakaria food system study: household-level, case-control study to identify risk factor for rickets in Bangladesh. Eur J Clin Nutr 59, 1291-1301.

21. Andiran N, Celik N, Akca H et al. (2012) Vitamin D deficiency in children and adolescents. J Clin Res Pediatr Endocrinol 4, 25-29.

22. Andiran N, Yordam N \& Ozon A (2002) Risk factors for vitamin $\mathrm{D}$ deficiency in breast-fed newborns and their mothers. Nutrition 18, 47-50.

23. Gharaibeh MA \& Stoecker BJ (2009) Assessment of serum $25(\mathrm{OH}) \mathrm{D}$ concentration in women of childbearing age and their preschool children in Northern Jordan during summer. Eur J Clin Nutr 63, 1320-1326.

24. Grant CC, Wall CR, Crengle S et al. (2009) Vitamin D deficiency in early childhood: prevalent in the sunny South Pacific. Public Health Nutr 12, 1893-1901.

25. Hintzpeter B, Scheidt-Nave C, Muller MJ et al. (2008) Higher prevalence of vitamin $\mathrm{D}$ deficiency is associated with immigrant background among children and adolescents in Germany. J Nutr 138, 1482-1490.

26. Mansbach JM, Ginde AA \& Camargo CA Jr (2009) Serum 25-hydroxyvitamin D levels among US children aged 1 to 11 years: do children need more vitamin D? Pediatrics 124, 1404-1410. 
27. Prentice A (2008) Vitamin D deficiency: a global perspective. Nutr Rev 66, 10 Suppl. 2, S153-S164.

28. Zhu Z, Zhan J, Shao J et al. (2012) High prevalence of vitamin $D$ deficiency among children aged 1 month to 16 years in Hangzhou, China. BMC Public Health 12, 126.

29. The MAL-ED Network Investigators (2014) The MAL-ED study: a multinational and multidisciplinary approach to understand the relationship between enteric pathogens, malnutrition, gut physiology, physical growth, cognitive development, and immune responses in infants and children up to 2 years of age in resource-poor environments. Clin Infect Dis 59, Suppl. 4, S193-S206.

30. Ahmed T, Mahfuz M, Islam MM et al. (2014) The MAL-ED cohort study in Mirpur, Bangladesh. Clin Infect Dis 59, Suppl. 4, S280-S286.

31. The DHS Program (2008) DHS Model Questionnaires. http://www.measuredhs.com/What-We-Do/Survey-Types/ DHS-Questionnaires.cfm\#CP_JUMP_16179 (accessed March 2013).

32. Wallace AM, Gibson S, de la Hunty A et al. (2010) Measurement of 25-hydroxyvitamin D in the clinical laboratory: current procedures, performance characteristics and limitations. Steroids 75, 477-488.

33. Wahed MA, Alvarez JO, Khaled MA et al. (1995) Comparison of the modified relative dose response (MRDR) and the relative dose response (RDR) in the assessment of vitamin A status in malnourished children. Am J Clin Nutr 61, $1253-1256$.

34. Tomkins A (1981) Nutritional status and severity of diarrhoea among pre-school children in rural Nigeria. Lancet 1, 860-862.

35. National Institute of Population Research and Training, Mitra and Associates, \& ICF International (2013) Bangladesh Demographic and Health Survey 2011. Dhaka and Calverton, MD: NIPORT, Mitra and Associates, and ICF International.

36. World Health Organization (20009) Global Prevalence of Vitamin A Deficiency in Populations At Risk 1995-2005. WHO Global Database on Vitamin A Deficiency. Geneva: WHO.

37. Brown KH, Rivera JA, Bhutta Z et al. (2004) International Zinc Nutrition Consultative Group (IZiNCG) technical document \#1. Assessment of the risk of zinc deficiency in populations and options for its control. Food Nutr Bull 25, 1 Suppl. 2, S99-S203.
38. Lips P (2001) Vitamin D deficiency and secondary hyperparathyroidism in the elderly: consequences for bone loss and fractures and therapeutic implications. Endocr Rev 22, 477-501.

39. Need AG, O'Loughlin PD, Morris HA et al. (2008) Vitamin D metabolites and calcium absorption in severe vitamin D deficiency. J Bone Miner Res 23, 1859-1863.

40. Bischoff-Ferrari HA, Giovannucci E, Willett WC et al. (2006) Estimation of optimal serum concentrations of 25-hydroxyvitamin D for multiple health outcomes. Am J Clin Nutr 84, 18-28.

41. Kuchuk NO, Pluijm SM, van Schoor NM et al. (2009) Relationships of serum 25-hydroxyvitamin D to bone mineral density and serum parathyroid hormone and markers of bone turnover in older persons. J Clin Endocrinol Metab 94, 1244-1250.

42. Clemens TL, Adams JS, Henderson SL et al. (1982) Increased skin pigment reduces the capacity of skin to synthesise vitamin $\mathrm{D}_{3}$. Lancet 1, 74-76.

43. Nair R \& Maseeh A (2012) Vitamin D: the 'sunshine' vitamin. $J$ Pharmacol Pharmacother 3, 118-126.

44. Matsuoka LY, Wortsman J, Dannenberg MJ et al. (1992) Clothing prevents ultraviolet-B radiation-dependent photosynthesis of vitamin $\mathrm{D}_{3}$. J Clin Endocrinol Metab $\mathbf{7 5}$, 1099-1103.

45. Roth DE, Al Mahmud A, Raqib R et al. (2013) Randomized placebo-controlled trial of high-dose prenatal third-trimester vitamin $\mathrm{D}_{3}$ supplementation in Bangladesh: the AViDD trial. Nutr J 12, 47.

46. Kazemi A, Sharifi F, Jafari N et al. (2009) High prevalence of vitamin $\mathrm{D}$ deficiency among pregnant women and their newborns in an Iranian population. $J$ Womens Health (Larchmt) 18, 835-839.

47. Sedrani SH, Abanmy A, Slaman H et al. (1992) Vitamin D status of Saudis: seasonal variations. Are Saudi children at risk of developing vitamin D deficiency rickets? Saudi Med J 13, 430-433.

48. Islam MZ, Lamberg-Allardt C, Karkkainen M et al. (2002) Vitamin D deficiency: a concern in premenopausal Bangladeshi women of two socio-economic groups in rural and urban region. Eur J Clin Nutr 56, 51-56.

49. Bhaskaram P (2002) Micronutrient malnutrition, infection, and immunity: an overview. Nutr Rev 60, 5 Pt 2, S40-S45.

50. Winichagoon P (2008) Coexistence of micronutrient malnutrition: implication for nutrition policy and programs in Asia. Asia Pac J Clin Nutr 17, Suppl. 1, 346-348. 